\title{
Multiple Domains and Categories of Employee Green Behaviors: More than Conservation
}

\author{
Deniz S. Ones \\ University of Minnesota \\ Stephan Dilchert \\ Baruch College, CUNY
}

\author{
Brenton M. Wiernik \\ Ghent University and University of South Florida \\ Rachael M. Klein \\ Korn Ferry
}

Ones, D. S., Wiernik, B. M., Dilchert, S., \& Klein, R. M. (2017). Multiple domains and categories of employee green behaviors: More than conservation. In V. Wells, D. Gregory-Smith, \& D. Manika (Eds.), Research handbook on employee pro-environmental behaviour. Cheltenham, United Kingdom: Edward Elgar.

\begin{abstract}
We describe a taxonomy of diverse types of workplace behaviors that contribute to or detract from environmental sustainability goals in organizational settings. The Green Five taxonomy was developed using critical incidents methodology and includes 5 major content-based meta-categories of employee green behaviors (EGB): Transforming, Avoiding Harm, Conserving, Influencing Others, and Taking Initiative. We discuss the behavioral and psychological meanings of these meta-categories, as well as their sub-categories. We also highlight key features of the Green Five taxonomy (e.g., it is content-based, it incorporates both positive and negative behaviors, it integrates with general models of job performance). Finally, we review existing measures of employee green behaviors in terms of their coverage of the employee green behavior construct domain. We identify future directions for research and applications.
\end{abstract}

Keywords: Pro-environmental behavior, environmental sustainability, innovation, pollution, ecofriendly behavior, conservation

Amidst ongoing deterioration of the global ecosystem (IPCC 2015), organizations are increasing concerned with ensuring that their operations contribute to, or at least do not detract from, environmental sustainability (Jabbour and Santos 2006). Organizations seek to enhance their environmental performance both out of general concern for ensuring global welfare, as well as out of recognition that environmental deterioration threatens access to natural resources necessary for their operations (Holme et al. 2000). To this end, organizations around the globe have implemented a variety of pro-environmental initiatives to improve their environmental performance (D'Mello et al. 2011), and numerous methods for tracking organizational environmental impacts have been proposed (Dilchert and Ones 2012).

While assessment of environmental performance at the organizational (and higher; Roy and Goll 2014; Wiernik 2012) levels is critical, it is important to recognize that organizational performance is a function of individual employees within the organization acting in ways that contribute to or detract from environmental sustainability. Organizations do not recycle, employees do. Organizations do not set environmental policy, leaders and managers do. Organizations do not innovate new sustainable products, designers and engineers do. Thus,

This work was supported by the Belgian American Educational Foundation through a fellowship to B. M. Wiernik. Correspondence concerning this manuscript should be addressed to Deniz S. Ones, Department of Psychology, University of Minnesota, Minneapolis, MN. Email: onesx001@umn.edu 
understanding the ways employees act to benefit the environment and how such behaviors can be promoted are critical for enhancing organizational environmental performance.

Despite the importance of understanding and managing employee environmentally-relevant behaviors, organizational practice, lay conceptualizations, and even scholarly research in this area often thinks too narrowly about the nature of these behaviors. For many individuals, proenvironmental behaviors begin and end with the "3 Rs"-reduce, reuse, recycle. Similarly, many studies and organizational interventions focus narrowly on single pro-environmental behaviors, such as turning off lights and electronics, purchasing eco-friendly products, or participating in environmental volunteering projects. This narrow focus often results hampers progress toward environmental goals, as any single behavior can have only limited beneficial impact (Kaiser et al. 2007). Scholarship that does not explicitly recognize and model different types of workplace behaviors that serve or detract from environmental sustainability goals results in a research literature that is theoretically fragmented, empirically incomplete, and inefficient for applied practice purposes.

To effectively promote employee proenvironmental behavior and appropriately research the antecedents and consequences of different types of green behaviors, there is a need for clear conceptual definitions of employee green behaviors and an organizing taxonomy of the diverse array of behaviors that can be performed. This is the aim of this chapter. In the sections below, we define employee green behaviors and describe how they fit into general models of job performance. Then, we describe a comprehensive taxonomy of employee green behaviors. Next, we discuss the features of available measures of employee green behaviors. Finally, we discuss how considering the full array of employee green behaviors can enhance organizational HRM practices that promote environmental sustainability.

\section{Defining Employee Green Behaviors}

Employee green behaviors (EGB) are "scalable actions and behaviors that employees engage in that are linked with and contribute to or detract from environmental sustainability" (Ones and Dilchert 2012: 87). There are several important features of this definition. First, the focus is on the environmental performance of individual employees. While organization-, department-, or group-level environmental performance may be of interest, it is the actions of individuals within these larger units that drives environmental benefit and harm. Within a single organization or team, employees can vary widely in their environmentally relevant behaviors, so understanding the nature and antecedents of individual-level employee green behaviors is necessary to change larger unit environmental performance.

Second, the definition focuses on employee environmental behaviors, not outcomes. By focusing on what employees actually do, EGB exclude environmental outcomes that are outside individual control. An employee's environmental footprint is impacted not only by their own actions, but also by their coworkers (e.g., other department members demanding on-site meetings), the organization (e.g., supplying energy-inefficient computers), and external stakeholders (e.g., government regulations). As is the case for other domains of job performance, managing employee environmental performance requires addressing the behaviors employees themselves can change (Campbell and Wiernik 2015).

Third, EGB are scalable or measurable. Employee environmental performance can be rated in terms of its overall degree of beneficial or harmful impact on the environment, and individual employee green behaviors can be scaled in terms of their importance for environmental sustainability goals, their difficulty to perform, and other features. Different employees have quantitatively different impacts on the environment; evaluating employee environmental performance requires assessing their behaviors. 
Fourth, the definition encompasses both positive green behaviors that benefit the environment and negative ungreen behaviors that are harmful to the environment. Employees can both engage in (or refrain from) green behaviors (e.g., create sustainable products, recycle) and engage in (or refrain from) ungreen behaviors (e.g., pollute, end a green volunteering program). Refraining from positive environmental behaviors is not the same as actively harming the environment. Green and ungreen behaviors both impact the environment, and both promoting green behaviors and inhibiting ungreen behaviors is necessary for effective environmental performance. Inclusion of both beneficial and harmful behaviors is one reason we prefer the label "employee green behaviors" over "employee proenvironmental behaviors," as the latter neglects the critical negative behavioral repertoire associated with this behavioral domain.

Notable features explicitly not a part of the definition of EGB is whether they are voluntary or extra-role. Some proposed definitions of employee pro-environmental behaviors specify that these behaviors are discretionary (e.g., Boiral 2009). This stricture is unnecessary. While some employee green behaviors may be voluntary (e.g., using public transit to commute), others may be required by the organization (e.g., following waste disposal protocols). For some jobs, employee green behaviors may even be part of an employee's formal job role (e.g., technicians installing solar panels; Dierdorff et al. 2009, 2013). For some categories of EGB (particularly Avoiding Harm, see below), we have observed that $31-73 \%$ of positive and negative employee green behaviors are explicitly required by the organization (Wiernik et al. 2013). By limiting their investigations to only voluntary green behaviors, researchers ignore these critical areas of employee impact on the natural environment.

Compared to pro-environmental behaviors performed in non-work settings ('individual behaviors contributing to environmental sustainability'; Mesmer-Magnus et al. 2012: 160), employee green behaviors have several distinctive features. First, because they are performed in work settings, EGB are often subject to social norms, power dynamics, and role expectations not present in private non-work settings (cf. Stern 2000), and EGB may be impelled by motives (e.g., concern with organizational reputation) not present in other settings (Klein 2014; see Wiernik et al. 2017 Chapter 3, this volume). Second, whereas nonwork pro-environmental behaviors are based on individual volitional choice (excepting limitations based on socioeconomic availability of green options), as noted above, EGB are subject to a degree of organizational oversight and may be explicitly required or prohibited.

\section{Employee Green Behaviors as Job Performance}

The above discussion of whether employee green behaviors must be voluntary raises the question how this construct domain fits into general models of job performance (Campbell and Wiernik 2015; Viswesvaran and Ones 2000; cf. Norton et al. 2015). Are EGB an entirely new dimension of job performance, or do they fit into one or more broader performance constructs? Some researchers argue that employee green behaviors should be conceptualized as a facet of contextual performance/organizational citizenship behavior ("performance that supports the social and psychological environment in which [technical] performance takes place;' Organ 1997: 95; cf. Motowidlo 2000). For example, Lamm et al. (2013: 165) defined organizational citizenship for the environment (OCB-E) as "voluntary behavior not specified in official job descriptions that, through the combined efforts of individual employees, help to make the organization and/or society more sustainable" (see also Boiral 2009; Boiral and Paillé 2012). These definitions mirror early definitions of general OCB by requiring that green behaviors be voluntary, extra-role, and unrewarded; these features are unnecessary, as employee green behaviors are simply workplace behaviors which impact the natural environment (these features have also been abandoned as part of the definition of OCB; Organ 1997). Moreover, employee green behaviors and OCB have different structures (Borman and Motowidlo 1997; LePine et al. 2002; Ones and Dilchert 2012; Podsakoff et 
al. 2000), and employee green behaviors are not limited to behaviors typically considered to be part of the OCB domain (e.g., helping, persistence, volunteering). In fact, depending on the nature of the job, EGB can be part of all dimensions of job performance, including core technical performance (e.g., mutual fund managers choosing investments based on companies' environmental performance, tractor operators driving more slowly to reduce fuel usage), counterproductive work behaviors (ignoring sustainable purchasing policies), communication (writing sustainability reports), effort/initiative (going out of one's way to act sustainably), hierarchical leadership (supporting subordinates' green ideas), and others. Campbell and Wiernik (2015) described EGB as a compound performance domain - a collection of performance behaviors spanning multiple substantive performance dimensions which are united by a common goal-rather a separate performance dimension unto themselves. Similarly, we suggest that different types of employee green behaviors can be thought of as calling upon multiple behavioral performance domains.

\section{The Green Five Taxonomy of Employee Green Behaviors}

Most research on employee green behaviors (and on pro-environmental behaviors generally; see Kaiser 1998) focuses on predicting single behaviors and often conceptualizes EGB as being limited to reducing resource use, reusing materials, and recycling. Construct valid, generalizable research on employee green behaviors and effective organizational management of employee environmental performance require considering a wider range of environmentally-relevant employee behaviors. Organizational environmental sustainability research and practice need a taxonomy that spans the full range of employee green behaviors to guide conceptualization, measurement, and intervention.

The Green Five taxonomy, introduced by Ones and Dilchert (2012), comprehensively describes the diversity of environmentally-relevant behaviors employees perform at work. It is a content-based taxonomy that groups environmental behaviors based on the similarity of the behaviors being performed, their common functional goals, and shared purported psychological underpinnings. The taxonomy is hierarchically organized, with overall environmental performance at the apex, five broad meta-categories below it, and increasingly narrow subcategories below them. Categories at each hierarchical level of the taxonomy include both positive and negative (green and ungreen) employee behaviors. The Green Five taxonomy is illustrated in Figure 1. In the sections below, we review the research that lead to the development of the Green Five taxonomy, describe the content of each behavioral category, and discuss applications and ongoing research on the structure of employee green behaviors.

\section{Development of the Green Five Taxonomy}

The Green Five taxonomy was developed in stages. In the initial development stage, 1,299 critical incidents were gathered from 274 interviews with individuals holding 189 different types of jobs in 157 organizations across twenty U.S. industries. Employees were asked to describe behaviors they had observed coworkers perform that had a (positive or negative) impact on the environment. The content of each critical incident was analyzed and sorted by multiple raters (cf. Anderson and Wilson 1997). Emerging behavioral categories were tested using hypothetical examples and confirmatory sorts of new critical incidents to evaluate whether they comprehensively and unambiguously spanned the green behavior domain. A new confirmatory sample of 773 critical incidents was gathered from 133 interviews with individuals holding 97 job types in 92 organizations across 16 U.S. industries. We also examined the cross-cultural applicability of the taxonomy by gathering 1,002 additional critical incidents from 208 interviews with employees holding 86 different job types in 70 organizations across 15 industries in 14 European countries (Belgium, Bulgaria, Czech Republic, Denmark, England, Finland, France, Germany, 
Greece, Ireland, Italy, Norway, Sweden, and Turkey; Hill et al. 2011).

The resulting taxonomy consists of $17^{1}$ functionally distinguishable behavioral categories with relatively homogeneous content. These 17 categories are organized under five broad metacategories (the Green Five). The current working Green Five taxonomy is illustrated in Figure 1. Next, we describe each meta-category and its subcategories, as well as their functional cores (the aim or goal the behaviors are intended to bring about) and common psychological underpinnings.

\section{Transforming ${ }^{2}$}

The behaviors in this meta-category are aimed at adapting and changing to make work products and processes more sustainable. Example behaviors in this meta-category include commuting by bicycle rather than driving, purchasing locally-produced goods, changing the order tasks are done to generate less waste, and using a tablet computer rather than printouts to process paperwork. Job-specific examples include many forms of green technical performance, such as a researcher investigating new agricultural plants that require fewer pesticides, an architect designing a low impact building, a store owner moving refrigerated items closer together to reduce cooling needs, and a procurement agent choosing sources based on their sustainability records.

The psychological core of Transforming behaviors is adaptability and openness to change. The four Transforming subcategories vary in the degree to which they require creative and innovative effort and ability from employees versus merely adopting existing sustainable solutions. At the high end, Creating Sustainable Products and Processes involves generating novel

\footnotetext{
${ }^{1}$ Ones and Dilchert's (2012) original taxonomy contained 16 subcategories. Subsequent research suggested that the Encouraging and Supporting Others should be divided into separate subcategories corresponding to environmental management and environmental leadership (cf. Campbell and Wiernik 2015). These behaviors have somewhat divergent antecedents, consequences, and feedback needs, but empirically they are strongly correlated.
}

ideas and new, innovative solutions that are more sustainable. This subcategory might also be called Eco-Innovation. The second subcategory, Embracing Sustainable Innovations, involves implementing emerging innovative ideas and applying them to one's specific situation (e.g., adapting a work procedure to use a new more sustainable technology). Its negative pole involves active hostility to innovative solutions and clinging to established, less sustainable procedures. The final two subcategories involve adopting more well-established green options. Choosing Responsible Alternatives involves choosing the most sustainable option (e.g., for equipment, raw materials, supplies, or energy) out of available alternatives. Changing How Work is Done involves optimizing existing processes to improve their environmental impact. These subcategories still require openness to change, but they require less innovation and creative effort from employees to adopt.

Transforming behaviors are the foundation of employee green behaviors; to some degree, all green behaviors require changing one's behavior and adapting to new ways of doing things (Maloney and Ward 1973). Factor analytically, Transforming behaviors tend to be the best indicators of the general factor of employee green behaviors (Wiernik et al. 2016b).

\section{Conserving}

This meta-category includes behaviors aimed at avoiding wastefulness and thus preserving resources. It encompasses behaviors traditionally described as the "3Rs" (reduce, reuse, recycle). About half of all behavioral incidents we have gathered through our research fall into the Conserving meta-category. Conserving includes preservation of a wide variety of resources-

\footnotetext{
2 In Ones and Dilchert's (2012) original taxonomy, this meta-category was called "Working Sustainably". This label was ambiguous, so it was changed to "Transforming" to better reflect the meaning of the construct. Its behavioral content is unchanged.
} 
water, energy, gas, other natural resources, supplies, raw materials, etc. Conserving behaviors may target diverse resources, but they are united in their common functional goal for avoiding wastefulness and their psychological underpinnings of frugality, thrift, and responsibility. Scales including only items assessing reducing use of water, energy, gas, and supplies and recycling of glass, paper, metal, and oil may target many resources, but they capture a very narrow range of environmentally-relevant behaviors (see the distinction between environmental behaviors and outcomes, above).

The Conserving subcategories range in their degree of effectiveness for resource preservation. Reducing Use of resources is the most responsible way to conserve because it minimizes initial environmental impact. Reusing and Repurposing are also effective for reducing impact, as they involve using the same materials multiple times, rather than disposing of them after a single use, either for the same function (Reusing) or for purposes other than those originally intended (Repurposing). Finally, Recycling conserves the least resources and only mitigates impact because it requires additional energy, raw materials (including fuel for transportation), and processing before resources can be recovered for further use. This category also includes composting organic waste which, while better than landfill, is less effective than if such waste can be repurposed or never produced in the first place. Hence, from a resource conservation point of view, Reducing Use is the most desirable and Recycling the least desirable option among Conserving subcategories.

\section{Avoiding Harm}

This meta-category includes behaviors aimed at avoidance and inhibition of negative environmental behavior, reducing impact, and mitigating/restoring environmental damage. The negative pole of this meta-category includes behaviors that harm the environment by diminishing the health of the Earth's ecosystems and disrupting natural biological, chemical, and physical processes that help the planet recover from distress. The most common behaviors in this category are Polluting or, at the positive end, proactively Preventing Pollution. In our critical incidents databases, most behaviors in this metacategory were negative. The other two Avoiding Harm sub-categories support the primary function of avoiding environmental damage. Monitoring Environmental Impact involves assessing behaviors, processes, and outcomes to anticipate the potential for long-term harm (e.g., calculating one's carbon footprint, assessing water quality around manufacturing sites). Strengthening Ecosystems includes actions aimed at repairing or recovering from existing environmental damages, either at small scales (e.g., cleaning up litter, purchasing carbon offsets, using plants to filter toxins from the air) or at large scales (e.g., mine reclamation, mitigating an oil spill, planting trees to replenish logged areas, stopping fishing to allow a fishery to recover).

The psychological core of most Avoiding Harm behaviors at the positive end is cautiousness, selfcontrol, and responsibility (versus carelessness and irresponsibility at the negative pole). Behaviors associated with proactively avoiding harm or repairing existing environmental damage also involve altruism, particularly if they involve repairing harm caused by others or are motivated out of concern for the welfare of future generations.

\section{Influencing Others}

This meta-category focuses on behaviors aimed at spreading sustainability behaviors to other individuals. Influencing Others behaviors enhance sustainability by exploiting economies of scale; one individual's pro-environmental behaviors can cause others to act more sustainably. Influencing Others is an inherently social category, so its psychological underpinnings are Extraversion, Agreeableness, and interpersonal skill. Specific behaviors in this meta-category correspond to general job performance behaviors related to leadership, management, and communication and are structured accordingly (see Campbell and Wiernik 2015). Leading, Encouraging, and Supporting (or simply, Green Leadership) includes interpersonal influence 
behaviors that encourage, support, incentivize, empower, motivate, and guide others to behave more environmentally responsibly, as well as behaviors that model effective environmental performance for others. Managing, Organizing, and Coordinating (or simply, Green Management) includes behaviors that help others' green behaviors to be easier or more effective, such as making opportunities for green behaviors accessible, providing sufficient resources to enable green behaviors, coordinating green behaviors across individuals, units, or organizations, and organizing plans or procedures for green behaviors. Educating and Training involves behaviors aimed at enhancing others' environmentally-relevant declarative and procedural knowledge. It includes short-term training on environmentally-responsible procedures and behaviors, awareness-raising interventions, and larger-scale environmental education and outreach activities. This subcategory also includes providing individuals feedback on their environmental performance. All of these behaviors can be directed toward subordinates, coworkers, and superiors, as well as individuals outside the organization, such as clients, industry and strategic partners, suppliers, community members, and other stakeholders.

\section{Taking Initiative}

The last Green Five meta-category includes behaviors that are proactive, entrepreneurial, and involve a certain level of personal risk or sacrifice. It is analogous to general job performance behaviors related to initiative and effort (Campbell and Wiernik 2015), as well as proactive performance constructs (e.g., personal initiative, voice, taking charge; Thomas et al. 2010). This meta-category includes behaviors that break the mold, take risks, and go against societal expectations. These behaviors also require willingness to forego certain benefits and to suffer potential negative consequences (e.g., financial loss, discomfort, social consequences) because of their performance. Taking Initiative behaviors serve the function of rejecting the (unsustainable) status quo and proactively changing the context for a more sustainable future. The psychological core of Taking Initiative is proactivity (Fuller and Marler 2009; Thomas et al. 2010). Unlike Influencing Others, behaviors included in Taking Initiative may or may not be social in nature, and they can be directed at Avoiding Harm, Transforming, or Conserving. The distinguishing feature of Taking Initiative is the exceptional effort, personal sacrifice, and proactivity involved in performing them (cf. the Effort, Persistence, Initiative factor in the job performance model by Campbell and Wiernik 2015).

The entrepreneurial aspect of this metacategory is manifested in its subcategory Initiating Programs and Policies. The programs and policies employees might initiate can address any aspect of environmental sustainability or domain of employee green behaviors (e.g., initiating a new organizational recycling program, forming a Green Team to plan sustainability programs, instituting a sustainable purchasing policy). The key feature that distinguishes behaviors in this subcategory from merely being behaviors in their targeted categories is that Initiating behaviors involve effort on the part of the actor to change the status to a new more sustainable reality. Initiating a program or policy involves creating or developing a new venture and thus requires some degree of risk taking and willingness to sacrifice (money, resources, or effort, for example).

Another Taking Initiative subcategory is Lobbying and Activism (these might also be called green voice behaviors; Thomas et al. 2010). These behaviors involve advocating for environmental causes, including to supervisors, organizational decision makers, governments, and other powerholding individuals and institutions. Again, risk is involved as Lobbying and Activism intends to change the status quo towards increased sustainability, without necessarily considering all possible outcomes to employees themselves. Overcoming organizational inertia and standing out requires courage.

The final Taking Initiative subcategory is Putting Environmental Interests First. This subcategory involves sacrificing one's own 
interests (personal, comfort, convenience, financial, social, etc.) in the name of environmental sustainability. For example, this subcategory includes turning down profitable but harmful projects and commuting via public transit despite it taking longer than driving.

Table 1 provides example positive and negative behaviors for each of the categories described above.

\section{Notable Features and Sufficiency of the Green Five Taxonomy}

The Green Five is a content-based taxonomybehaviors are clustered according to their common functional goals and psychological underpinnings. The 17 subcategories and 5 meta-categories described are conceptually distinguishable and are useful for evaluating the comprehensiveness of green behavior assessments and interventions and for targeting feedback to improve specific areas of environmental performance. The Green Five taxonomy should not be interpreted as a latent factor structure. Employee green behaviors in different meta-categories are expected to be intercorrelated. There is a strong general factor of employee environmental performance, whether assessed by self-reports, supervisor-reports, or objective measures (Ones and Dilchert 2013; Wiernik et al. 2016b), and specific behavioral subcategories across the Green Five metacategories may correlate if they share common antecedents, hurdles, or motives. That said, item factor analyses by Wiernik et al. (2016b) found that empirical green behavior factors generally resembled the Green Five meta-categories.

Conceptually, many specific behaviors belong to multiple Green Five meta-categories and subcategories. For example, helping a coworker plan a public transit commute belongs to both the Leading, Encouraging, and Supporting and the Changing How Work is Done subcategories. Similarly, organizing a new program to clean up litter in the local community belongs to both Initiating Programs and Policies and Strengthening Ecosystems. This is not a problem (cf. Norton et al. 2015); it simply reflects that individual green behaviors can serve multiple functional goals and are determined by multiple individual and situational antecedents. Forcing behaviors to belong exclusively to single categories and failing to acknowledge substantial factor cross-loadings ignores important features of these complex behaviors (cf. Boiral and Paillé 2012).

Compared to other proposed organizational schemes for employee green behaviors, the Green Five taxonomy has several advantages. Norton et al. (2015) proposed a division of EGB into voluntary versus required green behaviors. Their required (or task-related) EGB category reflects EGB performed as part of employees' core technical job duties and purportedly includes behaviors related to adhering to organizational environmental policies, changing methods of work, choosing responsible alternatives, and creating sustainable products and processes ( $p$. 105). By contrast, voluntary (or proactive) EGB involve personal initiative that exceeds organizational environmental expectations and purportedly includes prioritizing environmental interests, initiating environmental programs and policies, lobbying and activism, and encouraging others. This characterization is inappropriate. Behaviors in each of the subcategories of the Green Five may or may not be required by organizations or job roles. The Norton et al. taxonomy conflates motive (requirement versus others) with behavioral content. This distinction parallels early conceptualizations of organizational citizenship behavior that emphasized voluntariness over specific behavioral content; OCB researchers eventually recognized that OCB may or may not be required and rewarded and that a focus on the actual behaviors of interest (helping, persistence, etc.) is more fruitful (Organ 1997; Rotundo and Sackett 2002). Emphasis on whether a green behavior is required or not distracts from a focus on its behavioral content and the diversity of other motives and antecedents that may impel it.

Boiral and Paillé (2012) proposed a threefactor model of employee green behaviors. They argue that employee green behaviors should be conceptualized as "organizational citizenship 
behaviors directed toward the environment", so their model is designed to closely parallel the lower-order factors of general OCB (Borman and Motowidlo 1997; Podsakoff et al. 2000). Their model includes factors called "eco-helping" (supporting coworkers in performing sustainable behaviors), "eco-civic engagement" (participating in organizational pro-environmental events, keeping apprised of organizational proenvironmental initiatives), and "eco-initiatives" (proposing new sustainable ideas, volunteering to carry out green tasks). As noted above, there is no reason to expect that employee green behaviors and OCB to have the same structure, and green behaviors can be a part of all dimensions of job performance (not only OCB). Because Boiral and Paille's model imposes the OCB structure onto the green behavior domain, it focuses almost exclusively on behaviors related to Influencing Others and Taking Initiative, excluding the large majority of employee green behaviors performed in most workplaces (Ones and Dilchert 2012).

\section{Measuring Employee Green Behaviors}

To address concerns with low reliability, weak predictability, and poor construct coverage of single-item measures, in the past eight years, several research teams have developed multibehavior measures of employee green behaviors. We reviewed the literature on employee green behaviors and identified 25 multi-item scales. Single-item measures, measures designed for nonwork (versus workplace) use (e.g., Kaiser 1998; Stern et al. 1999), and measures based on objective counts (e.g., mass of recycled material, kWh of energy used) were excluded. Features of these scales (e.g., scale names, authors) are shown in Table 2. We content-analyzed each of these scales to determine the number of items assessing each Green Five meta-category.

Authors of most EGB measures described them in general terms and intended them to capture the green behavior domain broadly. Despite their broad descriptions, however, the item content of most scales is very narrow. Most scales include items from only one or two of the Green Five metacategories. For example, many scales included only items assessing recycling/reducing use (Conserving) and sustainable product choices (Transforming) behaviors. Scales conceptualized as "organizational citizenship behavior for the environment", consistent with general OCB's focus on interpersonal support and personal initiative, typically focused almost exclusively on Influencing Others and Taking Initiative behaviors, ignoring the more technical dimensions of EGB (Conserving, Avoiding Harm) that make up the majority of behaviors (Ones and Dilchert 2012) with the greatest impact (Stern 2000) in this domain.

Many scales included multiple vague, general EGB items without specific behavioral content (e.g., 'I adequately completed assigned duties in environmentally-friendly ways'; Bissing-Olson et al. 2013; 'I undertake environmental actions that contribute positively to the image of my organization'; Boiral and Paillé 2012; 'Perform environmental tasks that are not required by my company'; Graves et al. 2013). These types of items are likely to have the same deficiencies as measures of general job performance that use vague statements about "accomplishing work goals" or "completing assigned tasks effectively", including increased rater-specific error, idiosyncratic rater definitions of 'environmentallyfriendly' and implicit theories of green behavior, and inconsistent use of rating scales (Campbell and Wiernik 2015; Hoffman et al. 2012). While these general evaluative items may have some uses (such as for repeated measures in experience sampling research designs), for most research and applications, more concretely specified items will yield greater reliability and interpretability for both respondents and assessment users.

Across EGB measures, Avoiding Harm behaviors (preventing pollution, monitoring impact, restoring damaged ecosystems) were particularly poorly represented. Scales also almost exclusively measured positive green behaviors; negative (ungreen) behaviors were almost entirely absent from existing measures. Only a small number of scales included sufficient items from each of the Green Five meta-categories to truly comprehensively cover the employee green 
behavior construct space. These include scales by Norton (2016) and McConnaughy (2014), several scales by Ones and colleagues (Ones and Dilchert 2009; Wiernik et al. 2016b, 2016a), and a scale by Graves et al. (2013; though this scale had weak coverage of Avoiding Harm).

We identified a small number of scales designed to measure specific narrow dimensions of employee green behaviors. As focused measures, we would expect their items to cluster into one or a few Green Five categories. Such measures can be useful when researchers are interested in the unique nomological network of specific green behavior domains or when organizations are particularly concerned with promoting a specific class of green behavior (e.g., environmental innovation, green leadership, waste reduction). Some of these scales provide good coverage of their target behavioral domain (e.g., the Ramus and Steger 2000 scale assesses a wide range of green leadership behaviors). However, other scales are so narrowly defined that their items are essentially identical (e.g., the Carrico and Riemer 2011 scale contains six items asking about turning off lights and equipment when not in use), leading to inflated reliability estimates and narrow construct coverage (a phenomenon referred to as a "bloated specific" (Cattell 1978).

In future research and application, scale developers must be more deliberate in their choices about how to measure employee green behaviors. A scale can be comprehensive or focused in its coverage, depending on measurement needs, but researchers must describe the content and meaning of their scales accurately. If a scale contains exclusively Conserving or Influencing Others behaviors, it is not a measure of employee green behaviors broadly. If a specific category of green behavior (e.g., Conserving) is of interest, it is perfectly fine to focus on that category and assess it reliably, but conclusions must be limited in their scope accordingly. If the goal is to measure employee green behaviors comprehensively, scale developers must ensure that items representing each Green Five metacategory (and ideally each subcategory) are included. Importantly, if researchers aim to report subscale scores in addition to overall environmental performance, they must ensure that sufficient items are included for each dimension to ensure reliability (cf. Gignac and Watkins 2013). For either of these measurement aims, vague items asking about undifferentiated "environmentallyfriendly behaviors" have limited divergent validity or utility for feedback and decision-making, so they generally should be avoided.

One promising area for future research and practice is to develop employee green behavior measures that are tailored to fit specific jobs, industries, or organizations. Each of the reviewed scales was designed to be widely applicable across work contexts. Such measures are useful and permit commensurate measurement across studies, but they also often consist primarily of relatively low difficulty, everyday behaviors in a domain (cf. Bennett and Robinson 2000). By developing measures for more specific employee populations (e.g., supply chain managers, wind turbine technicians, architects, lawyers, researchers), researchers will be better able to capture these behaviors with higher fidelity in each context.

\section{Implications for Practice}

The behavioral taxonomy described in this chapter has implications for organizational human resource management practices that address environmental sustainability. The taxonomy should be used to inform the behaviors organizations choose to target with HRM programs and help to organize and evaluated programs' design and effectiveness. For any proenvironmental HRM program, practitioners must specify which specific employee green behaviors they wish to impact. Then, potential programs can be evaluated for whether they will be effective for promoting (or inhibiting) behaviors in these categories. If the goal of an HRM program is to target employee environmental performance broadly, the Green Five taxonomy can similarly be used to evaluate whether the full range of green behaviors has been covered and to identify areas where further attention may be needed.

The full range of HRM tools can be used to promote effective environmental performance in 
each Green Five category. Most organizations rely on motivational interventions designed to raise environmental awareness and concern, but interventions can be more effective if they are deeply embedded into organizational HRM practice. For example, job design can incorporate EGB into employee role responsibilities. Ergonomics can be used to place recycling and compost bins in locations convenient to employees. Organizational pro-environmental initiatives can be used in recruitment and green competencies added to job descriptions to attract applicants likely to be strong environmental performers. Hiring systems can be designed to assess green competencies and predict on-the-job green behaviors. Environmental values can be incorporated into organizational socialization processes, and employees can be trained on sustainable methods for performing their core work tasks. For performance management, organizations can set environmental performance goals for each employee and incorporate green behaviors into performance evaluation systems. Organizations can further design sustainabilityfocused career paths and incorporate sustainability into the portfolio of skill requirements for leadership and executive development and advancement.

For all environmental initiatives, HRM practitioners should gather data and conduct surveys to assess employees' attitudes and responses to organizational environmental messages and to evaluate the effectiveness of the initiatives. Environmental sustainability can be incorporated into all areas of HRM practice, and these practices should be designed to address the full range of green behaviors that can be performed by employees in all jobs, industries, and organizational levels. By addressing the diversity of employee green behaviors beyond traditional notions of conservation and the $3 \mathrm{Rs}$, organizations can advance their own strategic environmental goals and promote the long-term sustainability of the planet they operate on.

\section{References}

Anderson, L. and S. Wilson (1997), 'Critical incident technique', in D. L. Whetzel and G. R. Wheaton (eds), Applied Measurement Methods in Industrial Psychology, Palo Alto, CA: Davies-Black Publishing, pp. 89-112.

Bennett, R. J. and S. L. Robinson (2000), 'Development of a measure of workplace deviance', Journal of Applied Psychology, 85 (3), 349-60.

Bissing-Olson, M. J., A. Iyer, K. S. Fielding and H. Zacher (2013), 'Relationships between daily affect and pro-environmental behavior at work: The moderating role of pro-environmental attitude', Journal of Organizational Behavior, 34 (2), 15675.

Boiral, O. (2009), 'Greening the corporation through organizational citizenship behaviors', Journal of Business Ethics, 87 (2), 221-36.

Boiral, O. and P. Paillé (2012), 'Organizational citizenship behaviour for the environment: Measurement and validation', Journal of Business Ethics, 109 (4), $431-45$.

Borman, W. C. and S. J. Motowidlo (1997), 'Task performance and contextual performance: the meaning for personnel selection research', Human Performance, 10, 99-109.

Campbell, J. P. and B. M. Wiernik (2015), 'The modeling and assessment of work performance', Annual Review of Organizational Psychology and Organizational Behavior, 2, 47-74.

Cantor, D. E., P. C. Morrow and F. Montabon (2012), 'Engagement in environmental behaviors among supply chain management employees: An organizational support theoretical perspective', Journal of Supply Chain Management, 48 (3), 3351.

Carrico, A. R. and M. Riemer (2011), 'Motivating energy conservation in the workplace: An evaluation of the use of group-level feedback and peer education', Journal of Environmental Psychology, 31 (1), 1-13.

Cattell, R. B. (1978), The Scientific Use of Factor Analysis in Behavioral and Life Sciences, Boston, MA: Springer US.

Chou, C.-J. (2014), 'Hotels' environmental policies and employee personal environmental beliefs: Interactions and outcomes', Tourism Management, 40, 436-46.

Dierdorff, E. C., J. J. Norton, D. W. Drewes, C. M. Kroustalis, D. Rivkin and P. Lewis (2009), Greening of the World of Work: Implications for $O * N E T-S O C$ and New and Emerging Occupations, Raleigh, NC: National Center for O* NET 
Development, accessed 17 May 2015 at http://www.ctdol.state.ct.us/wia/memos/2009/ONE T-GreeningOfWorld.pdf.

Dierdorff, E. C., J. J. Norton, C. M. Gregory, D. Rivkin and P. Lewis (2013), 'O*NET's national perspective on the greening of the world of work', in A. H. Huffman and S. R. Klein (eds), Green Organizations: Driving Change with I-O Psychology, New York: Routledge, pp. 348-78.

Dilchert, S. and D. S. Ones (2012), 'Measuring and improving environmental sustainability', in S. E. Jackson, D. S. Ones, and S. Dilchert (eds), Managing Human Resources for Environmental Sustainability, San Francisco, CA: JosseyBass/Wiley, pp. 187-221.

D'Mello, S., D. S. Ones, R. M. Klein, B. M. Wiernik and S. Dilchert (2011), Green Company Rankings and Reporting of Pro-Environmental Efforts in Organizations, Poster presented at the annual conference of the Society for Industrial and Organizational Psychology, Chicago, IL, April, accessed at https://doi.org/10.1037/e518362013195.

Fuller, J. B., Jr. and L. E. Marler (2009), 'Change driven by nature: A meta-analytic review of the proactive personality literature', Journal of Vocational Behavior, 75 (3), 329-45.

Gignac, G. E. and M. W. Watkins (2013), 'Bifactor modeling and the estimation of model-based reliability in the WAIS-IV', Multivariate Behavioral Research, 48 (5), 639-62.

Graves, L. M., J. Sarkis and Q. Zhu (2013), 'How transformational leadership and employee motivation combine to predict employee proenvironmental behaviors in China', Journal of Environmental Psychology, 35, 81-91.

Hill, L., D. S. Ones, S. Dilchert, B. M. Wiernik, R. M. Klein and S. D'Mello (2011), Employee Green Behaviors in Europe: A Cross-Cultural Taxonomic Investigation, Symposium presented at the annual conference of the Society for Industrial and Organizational Psychology, Chicago, IL, April, accessed at https://doi.org/10.1037/e518362013449.

Hoffman, B. J., C. A. Gorman, C. A. Blair, J. P. Meriac, B. Overstreet and E. K. Atchley (2012), 'Evidence for the effectiveness of an alternative multisource performance rating methodology', Personnel Psychology, 65 (3), 531-63.

Holme, R., P. Watts, World Business Council and for Sustainable Development (2000), Corporate Social Responsibility: Making Good Business Sense, Conches-Geneva, Switzerland: World Business Council for Sustainable Development.
Homburg, A. and A. Stolberg (2006), 'Explaining proenvironmental behavior with a cognitive theory of stress', Journal of Environmental Psychology, 26 (1), 1-14.

IPCC (2015), Climate Change 2014: Mitigation of Climate Change. Contribution of Working Group III to the Fifth Assessment Report of the Intergovernmental Panel on Climate Change, Cambridge, United Kingdom: Cambridge University Press.

Jabbour, C. J. C. and F. C. A. Santos (2006), 'The evolution of environmental management within organizations: Toward a common taxonomy', Environmental Quality Management, 16 (2), $43-$ 59.

Kaiser, F. G. (1998), 'A general measure of ecological behavior', Journal of Applied Social Psychology, 28 (5), 395-422.

Kaiser, F. G., P. W. Schultz and H. Scheuthle (2007), 'The theory of planned behavior without compatibility? Beyond method bias and past trivial associations', Journal of Applied Social Psychology, 37 (7), 1522-44.

Kim, A., Y. Kim, K. Han, S. E. Jackson and R. E. Ployhart (2014), 'Multilevel influences on voluntary workplace green behavior: Individual differences, leader behavior, and coworker advocacy', Journal of Management, accessed at https://doi.org/10.1177/0149206314547386.

Klein, R. M. (2014), Employee Motives for Engaging in Environmentally Sustainable Behaviors: A MultiStudy Analysis, Doctoral dissertation, Minneapolis, MN: University of Minnesota.

Lamm, E., J. Tosti-Kharas and E. G. Williams (2013), 'Read this article, but don't print it: Organizational citizenship behavior toward the environment', Group \& Organization Management, 38 (2), 16397.

LePine, J. A., A. Erez and D. E. Johnson (2002), 'The nature and dimensionality of organizational citizenship behavior: A critical review and metaanalysis', Journal of Applied Psychology, 87 (1), 52-65.

Maloney, M. P. and M. P. Ward (1973), 'Ecology: Let's hear from the people: An objective scale for the measurement of ecological attitudes and knowledge', American Psychologist, 28 (7), 5836.

Manika, D., V. K. Wells, D. Gregory-Smith and M. Gentry (2015), 'The impact of individual attitudinal and organisational variables on workplace environmentally friendly behaviours', Journal of Business Ethics, 126 (4), 663-84.

McConnaughy, J. (2014), Development of an Employee Green Behavior Descriptive Norms Scale, 
Master's thesis, San Bernardino, CA: California State University, San Bernardino, accessed at http://scholarworks.lib.csusb.edu/etd/83.

Mesmer-Magnus, J., C. Viswesvaran and B. M. Wiernik (2012), 'The role of commitment in bridging the gap between organizational sustainability and environmental sustainability', in S. E. Jackson, D. S. Ones, and S. Dilchert (eds), Managing Human Resources for Environmental Sustainability, San Francisco, CA: Jossey-Bass/Wiley, pp. 155-86.

Montabon, F., R. Sroufe and R. Narasimhan (2007), 'An examination of corporate reporting, environmental management practices and firm performance', Journal of Operations Management, 25 (5), 998 1014.

Motowidlo, S. J. (2000), 'Some basic issues related to contextual performance and organizational citizenship behavior in human resource management', Human Resource Management Review, 10 (1), 115-26.

Nag, M. (2012), Pro-Environmental Behaviors in the Workplace: Is Concern for the Environment Enough?, Doctoral dissertation, College Park, MD: University of Maryland, accessed 14 August 2014 at http://hdl.handle.net/1903/13837.

Norton, T. (2016), A Multilevel Perspective on Employee Green Behaviour, Doctoral dissertation, Brisbane, Australia: University of Queensland, accessed at https://doi.org/10.14264/uq1.2016.285.

Norton, T. A., S. L. Parker, H. Zacher and N. M. Ashkanasy (2015), 'Employee green behavior: A theoretical framework, multilevel review, and future research agenda', Organization \& Environment, 28 (1), 103-25.

Norton, T. A., H. Zacher, S. L. Parker and N. M. Ashkanasy (2014), A Daily Diary Study on Predictors of Workplace Pro-Environmental Behaviors, Paper presented at the International Congress for Applied Psychology, Paris, France, July.

Norton, T. A., H. Zacher, S. L. Parker and N. M. Ashkanasy (2017), 'Bridging the gap between green behavioral intentions and employee green behavior: The role of green psychological climate', Journal of Organizational Behavior, accessed at https://doi.org/10.1002/job.2178.

Ones, D. S. and S. Dilchert (2009), Green Behaviors of Workers: A Taxonomy for the Green Economy, Paper presented at the annual meeting of the Academy of Management, Chicago, IL, 7 August.

Ones, D. S. and S. Dilchert (2012), 'Employee green behaviors', in S. E. Jackson, D. S. Ones, and S. Dilchert (eds), Managing Human Resources for Environmental Sustainability, San Francisco, CA: Jossey-Bass/Wiley, pp. 85-116.
Ones, D. S. and S. Dilchert (2013), 'Measuring, understanding, and influencing employee green behaviors', in A. H. Huffman and S. R. Klein (eds), Green Organizations: Driving Change with I-O Psychology, New York: Routledge, pp. 11548.

Organ, D. W. (1997), 'Organizational citizenship behavior: It's construct clean-up time', Human Performance, 10 (2), 85-97.

Podsakoff, P. M., S. B. MacKenzie, J. B. Paine and D. G. Bachrach (2000), 'Organizational citizenship behaviors: A critical review of the theoretical and empirical literature and suggestions for future research', Journal of Management, 26 (3), 513-63.

Ramus, C. A. and U. Steger (2000), 'The roles of supervisory support behaviors and environmental policy in employee "ecoinitiatives" at leading-edge European companies', Academy of Management Journal, 43 (4), 605-26.

Robertson, J. L. and J. Barling (2013), 'Greening organizations through leaders' influence on employees' pro-environmental behaviors', Journal of Organizational Behavior, 34 (2), 176-94.

Rotundo, M. and P. R. Sackett (2002), 'The relative importance of task, citizenship, and counterproductive performance to global ratings of job performance: A policy-capturing approach', Journal of Applied Psychology, 87 (1), 66-80.

Roy, A. and I. Goll (2014), 'Predictors of various facets of sustainability of nations: The role of cultural and economic factors', International Business Review, 23 (5), 849-61.

Scherbaum, C. A., P. M. Popovich and S. Finlinson (2008), 'Exploring individual-level factors related to employee energy-conservation behaviors at work', Journal of Applied Social Psychology, 38 (3), 81835.

Stern, P. C. (2000), 'Toward a coherent theory of environmentally significant behavior', Journal of Social Issues, 56 (3), 407-424.

Stern, P. C., T. Dietz, T. Abel, G. A. Guagnano and L. Kalof (1999), 'A value-belief-norm theory of support for social movements: The case of environmentalism', Human Ecology Review, 6 (2), 81-98.

Temminck, E., K. Mearns and L. Fruhen (2015), 'Motivating employees towards sustainable behaviour', Business Strategy and the Environment, 24 (6), 402-12.

Thomas, J. P., D. S. Whitman and C. Viswesvaran (2010), 'Employee proactivity in organizations: A comparative meta-analysis of emergent proactive constructs', Journal of Occupational and Organizational Psychology, 83 (2), 275-300. 
Viswesvaran, C. and D. S. Ones (2000), 'Perspectives on models of job performance', International Journal of Selection and Assessment, 8 (4), 216-26.

Wiernik, B. M. (2012), Measuring National Sustainability: Making Sense of a Multidimensional Construct, Symposium presented at the annual conference of the Society for Industrial and Organizational Psychology, San Diego, CA, April.

Wiernik, B. M., S. Dilchert and D. S. Ones (2013), 'Organizational environmental policies and employee behavior: comparing European and U.S. samples', in G. Hertel, C. Binnewies, S. Krumm, H. Holling, and M. Kleinmann (eds), Imagine the Future World: How Do We Want to Work Tomorrow? Abstract Proceedings of the 16th EAWOP Congress 2013, Münster, Germany: Münstersche Informationsund Archivsystem multimedialer Inhalte, p. 502.

Wiernik, B. M., S. Dilchert and D. S. Ones (2016a), 'Age and employee green behaviors: A meta-analysis', Frontiers in Psychology, 7, 194.

Wiernik, B. M., S. Dilchert, D. S. Ones and R. M. Klein (2016b), Item Factor Analysis of Employee Green Behaviors, Poster presented at the annual conference of the Society for Industrial and Organizational Psychology, Anaheim, CA, April.

Wiernik, B. M., D. S. Ones, S. Dilchert and R. M. Klein (2017), 'Individual antecedents of proenvironmental behaviors: Implications for employee green behavior', in V. Wells, D. Gregory-Smith, and D. Manika (eds), Research Handbook on Employee Pro-Environmental Behaviour, Cheltenham, United Kingdom: Edward Elgar.

Zhang, Y., Z. Wang and G. Zhou (2013), 'Antecedents of employee electricity saving behavior in organizations: An empirical study based on norm activation model', Energy Policy, 62, 1120-7. 
Table 1

Example Behaviors in Each Green Five Content Category

\begin{tabular}{|c|c|c|}
\hline $\begin{array}{l}\text { Employee green } \\
\text { behavior category }\end{array}$ & Example positive behavior & Example negative behavior \\
\hline \multicolumn{3}{|l|}{ Transforming ${ }^{\dagger}$} \\
\hline $\begin{array}{l}\text { Choosing responsible } \\
\text { alternatives }\end{array}$ & $\begin{array}{l}\text { Purchasing eco-friendly cleaning } \\
\text { chemicals; Purchasing energy- } \\
\text { efficient equipment }\end{array}$ & $\begin{array}{l}\text { Using raw materials from } \\
\text { unsustainable sources }\end{array}$ \\
\hline $\begin{array}{l}\text { Changing how work is } \\
\text { done }\end{array}$ & $\begin{array}{l}\text { Changing shipping routes to be more } \\
\text { efficient; Using public transit to } \\
\text { commute }\end{array}$ & $\begin{array}{l}\text { Changing to a less sustainable work } \\
\text { procedure; Implementing a } \\
\text { procedure with known } \\
\text { environmental costs in place of an } \\
\text { eco-friendly procedure }\end{array}$ \\
\hline $\begin{array}{l}\text { Creating sustainable } \\
\text { products and processes }\end{array}$ & $\begin{array}{l}\text { Removing toxic chemicals from a } \\
\text { manufacturing process; Creating a } \\
\text { mutual fund investing in } \\
\text { environmentally responsible } \\
\text { companies }\end{array}$ & $\begin{array}{l}\text { Ignoring environmental } \\
\text { considerations when designing new } \\
\text { products }\end{array}$ \\
\hline $\begin{array}{l}\text { Embracing sustainable } \\
\text { innovations }\end{array}$ & $\begin{array}{l}\text { Installing a green roof to reduce } \\
\text { cooling needs; Using virtual rather } \\
\text { than in-person meetings }\end{array}$ & $\begin{array}{l}\text { Insisting on computer printouts } \\
\text { when paperless options are available }\end{array}$ \\
\hline \multicolumn{3}{|l|}{ Conserving } \\
\hline Reducing use & $\begin{array}{l}\text { Printing double sided; Turning off } \\
\text { lights when unneeded }\end{array}$ & $\begin{array}{l}\text { Leaving a machine running when } \\
\text { not in use; Using resources } \\
\text { wastefully }\end{array}$ \\
\hline Reusing & $\begin{array}{l}\text { Washing plastic lab equipment } \\
\text { rather than discarding; Using } \\
\text { durable, rather than disposable } \\
\text { products and/or equipment }\end{array}$ & $\begin{array}{l}\text { Using single-use products when } \\
\text { durable alternatives are available }\end{array}$ \\
\hline Repurposing & $\begin{array}{l}\text { Diverting cooking oil to make } \\
\text { biodiesel; Collecting rainwater for } \\
\text { industrial use }\end{array}$ & $\begin{array}{l}\text { Sending expiring food to a landfill } \\
\text { rather than giving to local farmers } \\
\text { requesting it for animal feed }\end{array}$ \\
\hline $\begin{array}{l}\text { Recycling and } \\
\text { composting }\end{array}$ & $\begin{array}{l}\text { Recycling cans, bottles, paper; } \\
\text { Composting food waste }\end{array}$ & $\begin{array}{l}\text { Throwing away carpet scraps rather } \\
\text { than using available recycling } \\
\text { process }\end{array}$ \\
\hline
\end{tabular}

Avoiding Harm

Preventing pollution
Installing a collection system to prevent water contamination; Scrubbing emissions before release
Contaminating soil by dumping harmful chemicals; Improperly disposing of paint, oil or other hazardous substances 


\begin{tabular}{|c|c|c|}
\hline $\begin{array}{l}\text { Employee green } \\
\text { behavior category }\end{array}$ & Example positive behavior & Example negative behavior \\
\hline $\begin{array}{l}\text { Strengthening } \\
\text { ecosystems }\end{array}$ & $\begin{array}{l}\text { Maintaining wildlife areas around } \\
\text { work facilities; Cleaning up litter } \\
\text { around local area }\end{array}$ & $\begin{array}{l}\text { Clear cutting unnecessarily; } \\
\text { Growing pesticide-dependent crops }\end{array}$ \\
\hline $\begin{array}{l}\text { Monitoring } \\
\text { environmental impact }\end{array}$ & $\begin{array}{l}\text { Preparing a company emissions and } \\
\text { resource use report; Calculating the } \\
\text { lifecycle carbon cost of a product }\end{array}$ & $\begin{array}{l}\text { Failing to follow up on cleanup } \\
\text { effort after a negative environmental } \\
\text { event }\end{array}$ \\
\hline \multicolumn{3}{|l|}{ Influencing Others } \\
\hline $\begin{array}{l}\text { Leading, encouraging, } \\
\text { and supporting }\end{array}$ & $\begin{array}{l}\text { Providing incentives for biking or } \\
\text { using public transit commute; } \\
\text { Modeling effective green behaviors }\end{array}$ & $\begin{array}{l}\text { Mocking a coworker who takes food } \\
\text { waste home to compost }\end{array}$ \\
\hline $\begin{array}{l}\text { Managing, organizing, } \\
\text { and coordinating }\end{array}$ & $\begin{array}{l}\text { Making recycling bins accessible to } \\
\text { all employees; Arranging an } \\
\text { employee carpool network }\end{array}$ & $\begin{array}{l}\text { Creating unnecessary bureaucratic } \\
\text { obstacles for green behaviors }\end{array}$ \\
\hline Educating and training & $\begin{array}{l}\text { Training employees in proper } \\
\text { chemical handling; Providing } \\
\text { feedback on green performance }\end{array}$ & $\begin{array}{l}\text { Instructing employees to discard } \\
\text { unused materials }\end{array}$ \\
\hline \multicolumn{3}{|l|}{ Taking Initiative } \\
\hline $\begin{array}{l}\text { Initiating programs } \\
\text { and policies }\end{array}$ & $\begin{array}{l}\text { Creating a new sustainable } \\
\text { purchasing policy; Forming a Green } \\
\text { Team to plan sustainability programs }\end{array}$ & $\begin{array}{l}\text { Stopping a successful environmental } \\
\text { program }\end{array}$ \\
\hline Lobbying and activism & $\begin{array}{l}\text { Pushing organization to disclose } \\
\text { environmental record; Advocating } \\
\text { for environmental issues to } \\
\text { supervisor }\end{array}$ & $\begin{array}{l}\text { Advocating for programs or policies } \\
\text { that are environmentally harmful }\end{array}$ \\
\hline $\begin{array}{l}\text { Putting environmental } \\
\text { interests first }\end{array}$ & $\begin{array}{l}\text { Turning down an environmentally } \\
\text { harmful project; Not using an air } \\
\text { condition on hot days }\end{array}$ & $\begin{array}{l}\text { Prioritizing one's comfort or } \\
\text { convenience over environmental } \\
\text { concerns }\end{array}$ \\
\hline
\end{tabular}

Note. ${ }^{\dagger}$ Ones and Dilchert (2012) called this meta-category "Working Sustainably"; $\ddagger$ Ones and Dilchert (2012) grouped these behaviors under one subcategory, we separate them based on the conceptual distinction between leadership and management performance (cf. Campbell and Wiernik 2015). 
Table 2

Content Analysis of Employee Green Behaviors Measures: Mapping of Items to the Green Five

\begin{tabular}{|c|c|c|c|c|c|c|c|}
\hline \multirow[b]{2}{*}{ Scale } & \multirow[b]{2}{*}{ Subscales } & \multicolumn{5}{|c|}{ Green Five meta-categories } & \multirow[b]{2}{*}{ Gen. } \\
\hline & & $\mathbf{T}$ & $\mathbf{C}$ & AH & IO & TI & \\
\hline \multicolumn{8}{|l|}{ Measures intended to be comprehensively assess EGB } \\
\hline $\begin{array}{l}\text { Organizational Citizenship Behavior for the } \\
\text { Environment (Boiral and Paillé 2012) }\end{array}$ & $\begin{array}{l}\text { Eco-helping; Eco-civic engagement; Eco- } \\
\text { initiatives }\end{array}$ & & & 1 & 4 & 1 & 4 \\
\hline $\begin{array}{l}\text { Organizational Citizenship Behavior toward the } \\
\text { Environment (Lamm et al. 2013) }\end{array}$ & & & 12 & & & & \\
\hline $\begin{array}{l}\text { Organizational Citizenship Behaviour Directed } \\
\text { towards the Environment (Temminck et al. } \\
\text { 2015) }\end{array}$ & & 2 & & 1 & & 4 & \\
\hline $\begin{array}{l}\text { Pro-Environmental Behavior at the Workplace } \\
\text { Scale (Homburg and Stolberg 2006) }\end{array}$ & $\begin{array}{l}\text { Direct environmental behavior; Indirect } \\
\text { environmental behavior }\end{array}$ & & & & 2 & 1 & 2 \\
\hline $\begin{array}{l}\text { Environmental Management Practices Scale } \\
\text { (Montabon et al. 2007) }\end{array}$ & & 1 & & 1 & 1 & 1 & \\
\hline $\begin{array}{l}\text { Employee Environmental Behaviours (Chou } \\
\text { 2014) }\end{array}$ & & 2 & 5 & & & & \\
\hline $\begin{array}{l}\text { Employee Proenvironmental Behaviors (Graves } \\
\text { et al. 2013) }\end{array}$ & & 3 & 2 & 1 & 4 & 1 & 2 \\
\hline $\begin{array}{l}\text { Pro-Environmental Behaviors at Work Scale } \\
\text { (Nag 2012) }\end{array}$ & $\begin{array}{l}\text { Pro-Environmental Behaviors; } \\
\text { Pro-Environmental Behaviors at a Cost to } \\
\text { Self }\end{array}$ & 2 & 5 & & & 1 & \\
\hline $\begin{array}{l}\text { Workplace Pro-Environmental Behaviors } \\
\text { (Robertson and Barling 2013) }\end{array}$ & & & 5 & & & 1 & 1 \\
\hline $\begin{array}{l}\text { Workplace Environmentally Friendly } \\
\text { Behaviours (Manika et al. 2015) }\end{array}$ & $\begin{array}{l}\text { Recycling; Energy saving; Printing } \\
\text { reduction }\end{array}$ & & 14 & & & & \\
\hline Workplace Green Behaviors (Kim et al. 2014) & Voluntary WGB; Green Advocacy & 1 & 5 & & 3 & & \\
\hline $\begin{array}{l}\text { Daily Employee Green Behavior (Bissing-Olson } \\
\text { et al. 2013; Norton et al. 2014) }\end{array}$ & $\begin{array}{l}\text { Task-related EGB; Proactive EGB; Helping } \\
\text { EGB; Counterproductive EGB }\end{array}$ & & 1 & & 3 & 3 & 5 \\
\hline $\begin{array}{l}\text { Daily Employee Green Behavior (Norton et al. } \\
\text { 2017) }\end{array}$ & & & 5 & & & & \\
\hline $\begin{array}{l}\text { Daily Employee Green Behavior Scale-- } \\
\text { Alternative (Norton et al. 2017) }\end{array}$ & & & & & & & 3 \\
\hline Employee Green Behaviors (Norton 2016) & Task-related EGB; Proactive EGB & 15 & 8 & 2 & 2 & 4 & 1 \\
\hline
\end{tabular}




\begin{tabular}{|c|c|c|c|c|c|c|c|}
\hline \multirow[b]{2}{*}{ Scale } & \multirow{4}{*}{$\begin{array}{l}\text { Subscales } \\
\text { Working Sustainably; Conserving; Avoiding } \\
\text { Harm; Influencing Others; Taking Initiative }\end{array}$} & \multicolumn{5}{|c|}{ Green Five meta-categories } & \multirow[b]{2}{*}{ Gen. } \\
\hline & & $\mathbf{T}$ & $\mathbf{C}$ & AH & IO & TI & \\
\hline $\begin{array}{l}\text { Employee Green Behavior Norms Scale } \\
\text { (McConnaughy 2014) }\end{array}$ & & 6 & 8 & 3 & 4 & 6 & \\
\hline $\begin{array}{l}\text { Brief Employee Green Behavior Scale (Ones } \\
\text { and Dilchert 2009) }\end{array}$ & & 4 & 3 & 3 & 3 & 2 & \\
\hline $\begin{array}{l}\text { Employee Green Behavior Scale (Wiernik et al. } \\
\text { 2016b) }\end{array}$ & $\begin{array}{l}\text { Transforming; Conserving; Avoiding Harm; } \\
\text { Influencing Others; Taking Initiative }\end{array}$ & 25 & 20 & 17 & 11 & 12 & \\
\hline $\begin{array}{l}\text { Short Employee Green Behavior Scale (Wiernik } \\
\text { et al. 2016a) }\end{array}$ & $\begin{array}{l}\text { Transforming; Conserving; Avoiding Harm; } \\
\text { Influencing Others; Taking Initiative }\end{array}$ & 10 & 6 & 4 & 2 & 3 & \\
\hline \multicolumn{8}{|l|}{ Measures targeting specific EGB categories } \\
\hline $\begin{array}{l}\text { Innovative Environmental Management Scale } \\
\text { (Cantor et al. 2012) }\end{array}$ & & 1 & & & & 2 & \\
\hline $\begin{array}{l}\text { Conservation Behavior Scale (Carrico and } \\
\text { Riemer 2011) }\end{array}$ & & & 6 & & & & \\
\hline $\begin{array}{l}\text { Environmentally-Specific Transformational } \\
\text { Leadership (Robertson and Barling 2013) }\end{array}$ & & & & & 7 & & \\
\hline $\begin{array}{l}\text { Electricity Saving Behavior Scale (Zhang et al. } \\
\text { 2013) }\end{array}$ & & 2 & 5 & & & 1 & \\
\hline $\begin{array}{l}\text { Energy Saving Behaviors (Scherbaum et al. } \\
\text { 2008) }\end{array}$ & & & 6 & & & & \\
\hline $\begin{array}{l}\text { Sustainability Behavior Support Behaviorally } \\
\text { Anchored Rating Scale (Ramus and Steger } \\
\text { 2000) }\end{array}$ & $\begin{array}{l}\text { Support for innovation; Competence } \\
\text { building; Communication; Information } \\
\text { dissemination; Management of } \\
\text { goals/responsibilities; Rewards/recognition; }\end{array}$ & & & & 6 & & \\
\hline
\end{tabular}

Note. $\mathrm{T}$ = Transforming; $\mathrm{C}=$ Conserving; $\mathrm{AH}=$ Avoiding Harm; IO = Influencing Others; $\mathrm{TI}=$ Taking Initiative; Gen. = general employee green behaviors whose specific behavioral content could not be determined (e.g., 'I undertake environmental actions that contribute positively to the image of my organization'; Boiral and Paillé 2012); values are the number of items tapping each meta-category. 


\section{Figures}

Figure 1. Meta-categories and subcategories of employee green behaviors in the Green Five taxonomy.

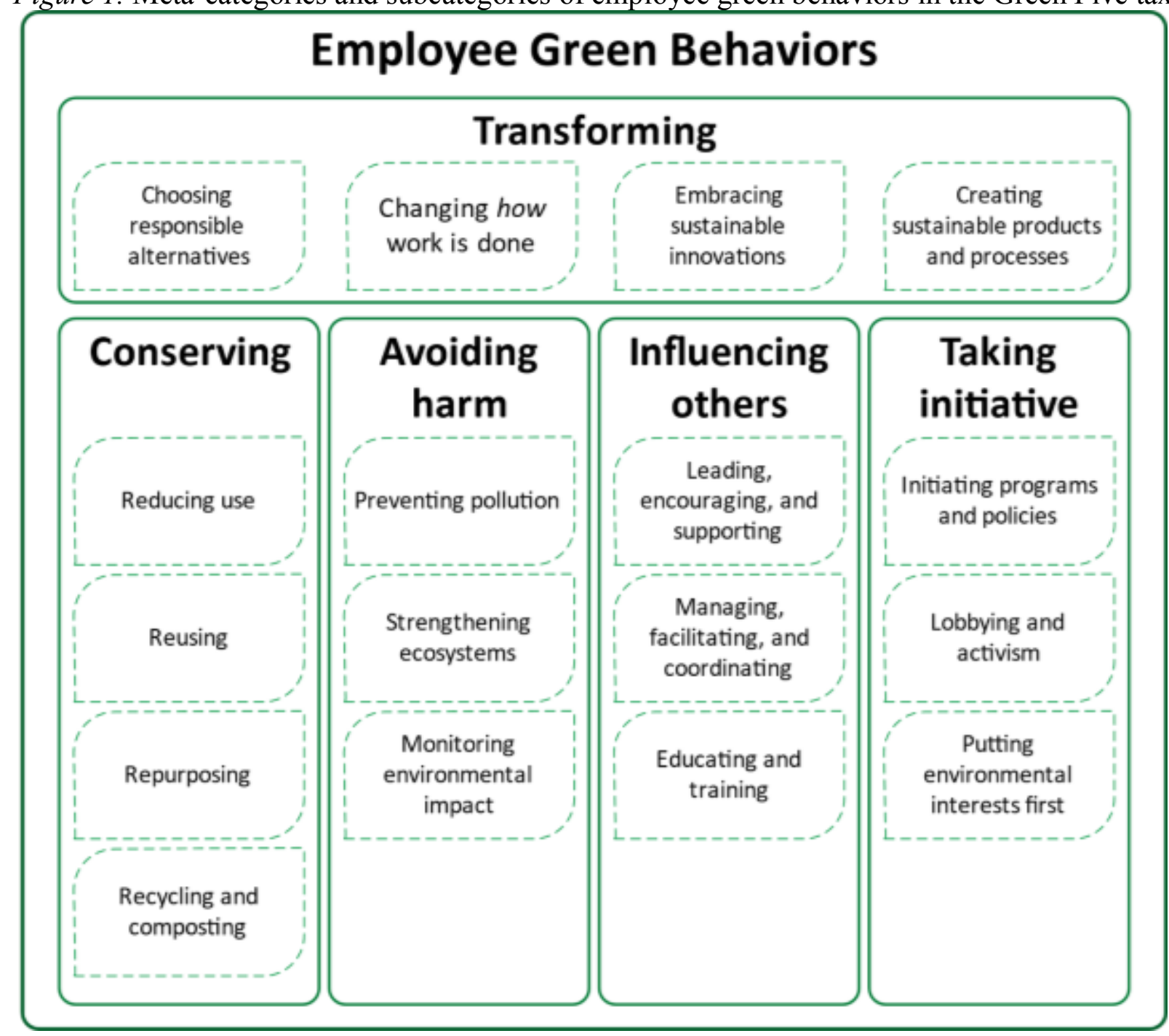

